\title{
Métodos para acelerar e uniformizar a emergência de plântulas de Schizolobium amazonicum ${ }^{1}$
}

\author{
Methods of accelerating and standardising the emergence of seedlings in \\ Schizolobium amazonicum
}

\author{
Eleandro Candido Dapont ${ }^{2}$, Josué Bispo da Silva ${ }^{3 *}$, Jakson Domingos de Oliveira ${ }^{2}$, Charline Zaratin Alves ${ }^{4}$ e \\ Alek Sandro Dutra 5
}

\begin{abstract}
RESUMO - A dormência intensa verificada em sementes de Schizolobium amazonicum dificulta o processo de formação de mudas. O objetivo deste trabalho foi testar procedimentos para acelerar e uniformizar a emergência de plântulas de paricá. Foram utilizadas sementes coletadas de diversas matrizes na Floresta Estadual do Antimary, Acre. Os tratamentos constaram de sementes intactas (testemunha), escarificação com ácido sulfúrico concentrado (imersão por 5; 10;15;20;25; 30; 35; 40; 45 e 50 min), imersão em água aquecida $\left(60^{\circ} \mathrm{C}, 80^{\circ} \mathrm{C}\right.$ e $\left.100^{\circ} \mathrm{C}\right)$, escarificação da porção basal da semente com lixa, escarificação com punção por meio de perfurações na maior porção lateral do tegumento, e escarificação com esmeril elétrico na lateral do tegumento. Os efeitos dos tratamentos foram avaliados por meio da emergência de plântulas (EP) e do índice de velocidade de emergência (IVE) em seis momentos de observação, além da frequencia relativa e do tempo médio de emergência nos melhores resultados. O delineamento estatístico foi o inteiramente casualizado com quatro repetições em esquema fatorial para a EP e em arranjo simples para o IVE. A máxima EP em menor tempo pode ser conseguida com uso do punção, imersão em água fervente $\left(100^{\circ} \mathrm{C}\right)$ e do esmeril elétrico.
\end{abstract}

Palavras-chave: Paricá. Dormência. Sementes florestais.

\begin{abstract}
The intense dormancy seen in seeds of Schizolobium amazonicum, known locally as paricá, makes the formation process of seedlings difficult. The aim of this work was to test procedures to accelerate and standardise the emergence of seedlings in the paricá. The seeds used were collected from various matrices in the Antimary State Forest, in the Brazilian state of Acre. Treatments consisted of intact seeds (control), scarification with concentrated sulphuric acid (immersion for $5,10,15,20,25,30,35,40,45$ and $50 \mathrm{~min}$ ), immersion in heated water $\left(60^{\circ} \mathrm{C}, 80^{\circ} \mathrm{C}\right.$ and $\left.100{ }^{\circ} \mathrm{C}\right)$, scarification of the basal part of the seed with sandpaper, scarification with a punch by means of perforations in the largest lateral portion of the husk, and scarification with an electric emery grinder on the side of the husk. The effects of the treatments were evaluated using seedling emergence (EP) and the emergence speed index (EVI) at six observation times, as well as the relative frequency and average time of emergence for the best results. The statistical design was completely randomised with four replications in a factorial scheme for EP, and a single array for the IVE. Maximum EP can be achieved in less time by using the punch, immersion in boiling water $\left(100^{\circ} \mathrm{C}\right)$ and the electric grinder.
\end{abstract}

Key words: Paricá. Dormancy. Forest seeds.

\footnotetext{
*Autor para correspondência

${ }^{1}$ Recebido para publicação em 16/12/2013; aprovado em 26/03/2014

Artigo retirado da Monografia de Mestrado do primeiro autor

${ }^{2}$ Centro de Ciências Biológicas e da Natureza, Universidade Federal do Acre, Rod. BR 364, s/n, Rio Branco-AC, Brasil, 69.920-900

${ }^{3}$ Centro de Ciências Biológicas e da Natureza, Universidade Federal do Acre, Rod. BR 364, s/n, Rio Branco-AC, Brasil, 69.920-900, josuebispo@bol.com.br

${ }^{4}$ Universidade Federal de Mato Grosso do Sul, Campus de Chapadão do Sul, Estrada Fazenda Campo Bom, s/n, Chapadão do Sul-MS, Brasil, 79.560-000

${ }_{5}^{5}$ Departamento de Fitotecnia, Centro de Ciências Agrárias, Universidade Federal do Ceará, Campus do Pici, Av. Mister Hull, 2977, Bloco 847, Fortaleza-CE, Brasil, 60.356-000, alekdutra@ufc.br
} 


\section{INTRODUÇÃO}

As sementes de Schizolobium amazonicum (Leguminoseae: Caesalpinioideae) utilizadas na produção de mudas são coletadas a partir de indivíduos adultos que se desenvolvem em áreas de floresta nativa e sua germinação é de aproximadamente 28\% (MARUYAMA; UGAMOTO, 1989). Quando a semente é coletada com a testa, ainda conservando a cor verde ou tegumentos tenros, a germinação é alta (90\%) no quarto dia após a semeadura. Entretanto, o manejo é difícil pelo elevado teor de água e suscetibilidade ao ataque de microrganismos, motivo pelo qual são coletadas no inicio da dispersão espontânea, quando adquirem coloração café-claro (SOUSA; CARVALHO; RAMOS, 2005). Nessas condições, a germinação é baixa (16\%), e taxas acima de $90 \%$ podem ser obtidas, mas com aproximadamente 2310 dias (CRUZ; CARVALHO, 2006; CARVALHO, 2007).

Esse tempo prolongado para a germinação é uma forte evidência de que as sementes dessa espécie são acometidas por dormência física ou tegumentar capaz de limitar a rápida e uniforme germinação das sementes (CRUZ; MARTINS; CARVALHO, 2001). Nesse sentido Shimizu et al. (2011) comprovaram de forma precisa a dificuldade dessas sementes para se hidratarem quando apresentam o tegumento intacto, ficando com teor de água praticamente zero, mesmo após 72 horas imersas em água, ao passo que as sementes escarificadas iniciaram a embebição 12 horas após a imersão e absorveram volume de água correspondente a aproximadamente $200 \%$ de sua massa inicial ao final das avaliações.

A dormência causada pela restrição à embebição das sementes é característica da família Leguminosae (PEREZ, 2004) que, por apresentarem frutos deiscentes, as sementes têm o tegumento lignificado, o que confere maior proteção (DAMIÃO FILHO; MORO, 2005), cuja ocorrência é relativamente frequente em espécies de regiões tropicais, onde o excesso de umidade seria o problema a ser contornado (CARVALHO; NAKAGAWA, 2000). A impermeabilidade tegumentar, característica controlada geneticamente, varia entre espécies, variedades e cultivares, podendo ser influenciada pelas condições ambientais durante a maturação ou até mesmo no armazenamento (GUERRA et al., 1982).

Para superação da impermeabilidade tegumentar, Brasil (2009) fornece uma lista de pré-tratamentos para todas as espécies listadas. Entretanto, embora Schizolobium amazonicum seja de importância reconhecida, não existe ainda um protocolo oficial para favorecer o processo germinativo de suas sementes.

Vários pesquisadores procuraram desenvolver métodos para eliminação de dormência em paricá, como a escarificação térmica, a ácida e a mecânica, com resultados positivos por meio da imersão em água a $100^{\circ} \mathrm{C}$, corte do tegumento (BIANCHETTI; TEIXEIRA; MARTINS, 1997) e escarificação física com esmeril elétrico, com lixa e com ácido sulfúrico (CRUZ; CARVALHO, 2006; SILVANETO et al., 2007; CRUZ; CARVALHO; QUEIROZ, 2007; NEVES; DALCHIAVON; CARGNIN-STIELER, 2010; SHIMIZU et al., 2011), principalmente esse último, cujo uso tem mostrado resultados promissores para sementes de várias espécies florestais.

A considerável variação na metodologia e nos resultados dos trabalhos para superação de dormência reforça a necessidade da realização de novos trabalhos com sementes de paricá. O objetivo foi identificar metodologia adequada para reduzir o tempo e uniformizar a emergência de plântulas de Schizolobium amazonicum.

\section{MATERIAL E MÉTODOS}

Os trabalhos foram conduzidos no Laboratório de Sementes do Parque Zoobotânico da Universidade Federal do Acre e no Laboratório de Análise de Sementes da Fundação de Tecnologia do Acre, Rio Branco, AC, com sementes coletadas de diversas matrizes na Floresta

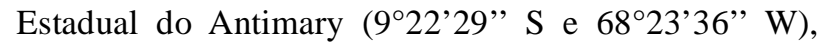
municípios de Bujari e Sena Madureira, AC. As sementes permeneceram armazenadas em câmara fria $\left(10{ }^{\circ} \mathrm{C}\right.$ e $70 \%$ UR ar) até o início dos trabalhos. O teor de água das sementes foi determinado pelo método da estufa (105 \pm $3{ }^{\circ} \mathrm{C}$ por 24 horas) (BRASIL, 2009), por meio de duas repetições de $5 \mathrm{~g}$ de sementes, e os resultados expressos em porcentagem.

Os tratamentos para superação da dormência constaram de sementes intactas (testemunha); escarificação com ácido sulfúrico concentrado (imersão) por $5 ; 10 ; 15 ; 20 ; 25 ; 30 ; 35 ; 40 ; 45$ e 50 minutos e lavagem na sequência em água corrente por cinco minutos; imersão em água aquecida a $60^{\circ} \mathrm{C}, 80^{\circ} \mathrm{C}$ e $100^{\circ} \mathrm{C}$ e, imediatamente após cada período foi desligada a fonte de calor e as sementes permaneceram na água até que atingiram a temperatura ambiente; escarificação da porção basal da semente com lixa para madeira $\mathrm{n}^{\circ} 50$ sem danificar o embrião; escarificação com punção, por meio de três perfurações na maior porção lateral do tegumento; escarificação com esmeril elétrico por dois segundos, na porção lateral, até o aparecimento parcial do cotilédone.

Para avaliar a influência dos tratamentos sobre a germinação quatro repetições de 25 sementes de cada tratamento foram desinfestadas por imersão em hipoclorito de sódio (2\%) por 5 minutos, lavadas em água corrente e colocadas para secar sobre folhas de papel germitest à sombra. Após a secagem, foram semeadas a $3 \mathrm{~cm}$ de profundidade 
dentro de caixas plásticas de 40 × 30 × $8 \mathrm{~cm}$ contendo substrato formado pela mistura de areia e Plantmax ${ }^{\circledR}$, na proporção 1:1 (v/v), previamente submetidos a $120{ }^{\circ} \mathrm{C}$ por duas horas. A primeira irrigação ocorreu logo após a semeadura. As avaliações ocorreram do $1^{\circ}$ ao $30^{\circ}$ dia, quando foram computadas as plântulas normais, ou seja, aquelas cujo epicótilo se encontrava acima da superfície do substrato (BRASIL, 2009), e as anormais. O cálculo da porcentagem de emergência de plântulas (EP) seguiu modelo proposto por Labouriau e Valadares (1976), conforme a equação 1.

$E P(\%)=(N * 100) / A$

em que $N=$ número de plântulas emergidas e $A=$ número total de sementes colocadas para germinar. Foram consideradas emergidas as plântulas cujo epicótilo encontrava-se acima do substrato e apresentava as estruturas essenciais totalmente desenvolvidas no momento das avaliações.

$O$ índice de velocidade de emergência (IVE) foi determinado paralelamente ao teste de emergência de plântulas, para cada tratamento, somando-se o número de plântulas emergidas a cada dia, divididas pelo respectivo número de dias transcorridos desde a semeadura (NAKAGAWA, 1999), dados que geraram um índice de vigor, conforme proposto por Maguire (1962).

Para as sementes intactas e os tratamentos com os melhores resultados foram determinados os polígonos da frequência relativa de emergência (FRE), calculada pela fórmula citada em Labouriau (1983), contabilizando-se o número de plântulas que emergiram por dia, até a última avaliação. Foi também determinado o tempo médio de emergência (TME), segundo fórmula citada por Labouriau e Valadares (1976) e Labouriau (1983).

O delineamento estatístico foi o inteiramente casualizado com quatro repetições. Os dados de EP foram avaliados aos $5 ; 10 ; 15 ; 20 ; 25$ e 30 dias após a semeadura e analisados em esquema fatorial 17 x 6 (tratamentos para superação da dormência x momentos de avaliação), e os de IVE em arranjo simples. Ao final foram submetidos à análise de variância e as médias comparadas pelo teste Tukey $(\mathrm{P} \leq 0,05)$. Os dados de EP foram transformados em $\operatorname{arcosen} \sqrt{ }(\mathrm{x} / 100)$, mas os valores apresentados não estão transformados (SILVA; AZEVEDO, 2009).

\section{RESULTADOS E DISCUSSÃO}

As sementes apresentaram teor de água de 5,11\% no início dos testes, valor semelhante ao encontrado por Cruz e Carvalho (2006) em sementes da mesma espécie (5,3\%). A impermeabilidade do tegumento é considerada o principal mecanismo responsável por manter as sementes com baixo teor de água, o que, nesse caso, é visto como uma vantagem porque evita o metabolismo mais intenso, reduz a atividade respiratória e, dessa forma, diminui o consumo de reservas indispensáveis à germinação e ao crescimento inicial da plântula (ZAIDAN; BARBEDO, 2004). Outras vantagens que podem ser citadas são a maior tolerância a atrasos na colheita, maior potencial de armazenamento e menor sensibilidade a injúrias mecânicas e a danos causados por fungos (MARCOS FILHO, 2005).

A emergência de plântulas (EP) a partir de sementes não escarificadas foi de $4 \%$ (Tabela 1), confirmando a dormência citada por vários autores. Nas sementes de leguminosas, além da epiderme apresentar o aspecto de uma camada paliçádica formada por células com paredes espessas e quase sempre lignificadas, há a possibilidade de essas células serem preenchidas por compostos fenólicos (PAOLI, 2006), substâncias que intensificam o estado de dormência.

Em todos os tratamentos, nenhuma plântula emergiu aos cinco dias após a semeadura (DAS), assim como no trabalho de Cruz e Carvalho (2006) aos seis dias. $\mathrm{Na}$ escarificação química com ácido sulfúrico, apenas nos períodos de 40 e 45 minutos nas contagens a partir de 15 dias a EP diferiu da testemunha. Para Garcia, Souza e Colares (2005), a imersão de sementes de paricá por 5; 10; 15 e 20 minutos também não foi eficaz na superação da dormência. Já Cruz, Carvalho e Queiroz (2007) tiveram resultados satisfatórios com o uso do ácido sulfúrico, mas com 60 minutos de imersão.

Nota-se também que em 50 minutos houve redução significativa em relação ao período anterior na mesma época de avaliação. O tempo máximo de exposição ao ácido deve ser quantificado precisamente para cada espécie, porque períodos longos podem ser prejudiciais ao processo germinativo (SCHMIDT, 2000), e a variabilidade genética existente em paricá (OHASHI, 2005) pode ser a razão dessa maior sensibilidade a período maior que 50 minutos, em comparação aos 60 minutos determinados por Leão e Carvalho (1995) e Cruz, Carvalho e Queiroz (2007). Considerando que para sementes dessa espécie, quando se adota métodos para eliminação da dormência são desejáveis valores a partir de $75 \%$ de germinação (SOUSA; CARVALHO; RAMOS, 2005), a escarificação com $\mathrm{H}_{2} \mathrm{SO}_{4}$ não se mostrou adequada.

A partir de 10 dias a escarificação com esmeril igualou-se à água a $100{ }^{\circ} \mathrm{C}$ e superou todos os outros tratamentos. Pelo método de imersão das sementes em água fervente a germinação praticamente se estabilizou aos 20 DAS, enquanto na escarificação com lixa, esmeril e punção isso ocorreu já no $15^{\circ}$ dia, momento de avaliação em que a escarificação com água a $100{ }^{\circ} \mathrm{C}$, com lixa, com esmeril e com punção destacaram-se dos demais, com EP de 82; 81; 92 e 89\%, respectivamente, resultado mantido aos 20; 25 e 30 dias, 
Tabela 1 - Emergência (\%) e índice de velocidade de emergência de plântulas (IVE) provenientes de sementes de Schizolobium amazonicum submetidas a diferentes tratamentos para aceleração e uniformização da germinação

\begin{tabular}{|c|c|c|c|c|c|c|c|}
\hline \multirow{3}{*}{ Tratamento } & \multicolumn{6}{|c|}{ Dias após a semeadura } & \multirow{3}{*}{ IVE } \\
\hline & 5 & 10 & 15 & 20 & 25 & 30 & \\
\hline & \multicolumn{6}{|c|}{ 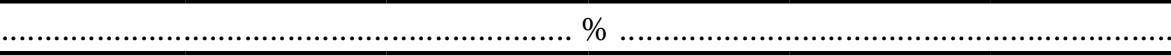 } & \\
\hline Intactas & $0 \mathrm{aB}$ & $0 \mathrm{cB}$ & $0 \mathrm{~dB}$ & $0 \mathrm{eAB}$ & $4 \mathrm{eAB}$ & 4 efA & $0,04 \mathrm{e}$ \\
\hline $\mathrm{H}_{2} \mathrm{SO}_{4} 5$ & $0 \mathrm{aA}$ & $0 \mathrm{cA}$ & $1 \mathrm{dA}$ & $1 \mathrm{eA}$ & $6 \mathrm{eA}$ & $11 \mathrm{efA}$ & $0,07 \mathrm{e}$ \\
\hline $\mathrm{H}_{2} \mathrm{SO}_{4} 10$ & $0 \mathrm{aA}$ & $0 \mathrm{cA}$ & $1 \mathrm{dA}$ & $1 \mathrm{eA}$ & $1 \mathrm{eA}$ & $4 \mathrm{fA}$ & $0,02 \mathrm{e}$ \\
\hline $\mathrm{H}_{2} \mathrm{SO}_{4} 15$ & $0 \mathrm{aA}$ & $1 \mathrm{cA}$ & $1 \mathrm{dA}$ & $2 \mathrm{deA}$ & $4 \mathrm{eA}$ & 4 efA & $0,06 \mathrm{e}$ \\
\hline $\mathrm{H}_{2} \mathrm{SO}_{4} 20$ & $0 \mathrm{aA}$ & $0 \mathrm{cA}$ & $2 \mathrm{dA}$ & $4 \mathrm{deA}$ & $5 \mathrm{deA}$ & $7 \mathrm{efA}$ & $0,07 \mathrm{e}$ \\
\hline $\mathrm{H}_{2} \mathrm{SO}_{4} 25$ & $0 \mathrm{aA}$ & $1 \mathrm{cA}$ & $4 \mathrm{dA}$ & $5 \mathrm{deA}$ & $6 \mathrm{deA}$ & 8 efA & $0,13 \mathrm{de}$ \\
\hline $\mathrm{H}_{2} \mathrm{SO}_{4} 30^{\prime}$ & $0 \mathrm{aA}$ & $0 \mathrm{cA}$ & $4 \mathrm{dA}$ & $6 \mathrm{dA}$ & $6 \mathrm{de} A$ & 8 efA & $0,14 \mathrm{de}$ \\
\hline $\mathrm{H}_{2} \mathrm{SO}_{4} 35^{\prime}$ & $0 \mathrm{aB}$ & $0 \mathrm{cB}$ & $2 \mathrm{dAB}$ & $5 \mathrm{de} A B$ & $9 \operatorname{cde} A$ & $9 \mathrm{deA}$ & $0,12 \mathrm{de}$ \\
\hline $\mathrm{H}_{2} \mathrm{SO}_{4} 40$ & $0 \mathrm{aB}$ & $2 \mathrm{cB}$ & $15 \mathrm{bcA}$ & $18 \mathrm{bcA}$ & $25 \mathrm{bcA}$ & $25 \mathrm{cdA}$ & $0,44 \mathrm{~cd}$ \\
\hline $\mathrm{H}_{2} \mathrm{SO}_{4} 45$ & $0 \mathrm{aC}$ & $11 \mathrm{bB}$ & $28 \mathrm{bA}$ & $33 \mathrm{bA}$ & $39 \mathrm{bA}$ & $39 \mathrm{cA}$ & $0,77 \mathrm{bc}$ \\
\hline $\mathrm{H}_{2} \mathrm{SO}_{4} 50$ & $0 \mathrm{aB}$ & $1 \mathrm{cB}$ & $3 \mathrm{~dB}$ & $12 \mathrm{cdA}$ & $15 \mathrm{cdA}$ & $15 \mathrm{deA}$ & $0,20 \mathrm{de}$ \\
\hline Água $60^{\circ} \mathrm{C}$ & $0 \mathrm{aA}$ & $0 \mathrm{cA}$ & $3 \mathrm{dA}$ & $3 \mathrm{de} A$ & $4 \mathrm{eA}$ & $5 \mathrm{efA}$ & $0,07 \mathrm{e}$ \\
\hline Água $80^{\circ} \mathrm{C}$ & $0 \mathrm{aC}$ & $17 \mathrm{bB}$ & $36 \mathrm{bAB}$ & $43 \mathrm{bA}$ & $50 \mathrm{bA}$ & $54 \mathrm{bc}$ & $0,98 \mathrm{~b}$ \\
\hline Água $100^{\circ} \mathrm{C}$ & $0 \mathrm{aC}$ & $55 \mathrm{aB}$ & $82 \mathrm{aAB}$ & $88 \mathrm{aA}$ & $91 \mathrm{aA}$ & $91 \mathrm{aA}$ & $2,10 \mathrm{a}$ \\
\hline Lixa & $0 \mathrm{aC}$ & $49 \mathrm{aB}$ & $81 \mathrm{aA}$ & $81 \mathrm{aA}$ & $85 \mathrm{aA}$ & $85 \mathrm{aA}$ & $1,98 \mathrm{a}$ \\
\hline Punção & $0 \mathrm{aC}$ & $51 \mathrm{aB}$ & $89 \mathrm{aA}$ & $89 \mathrm{aA}$ & $89 \mathrm{a}$ & $89 \mathrm{aA}$ & $2,10 \mathrm{a}$ \\
\hline Esmeril & $0 \mathrm{aB}$ & $68 \mathrm{aA}$ & $92 \mathrm{aA}$ & $94 \mathrm{aA}$ & $95 \mathrm{aA}$ & $95 \mathrm{aA}$ & $2,26 \mathrm{a}$ \\
\hline C.V. (\%) & \multicolumn{6}{|c|}{30,98} & 19,10 \\
\hline
\end{tabular}

Médias seguidas por letras distintas, minúscula na coluna e maiúscula na linha, diferem entre si ao nível de 5\% de probabilidade no Teste de Tukey

apresentando na contagem final 91, 85, 95 e $89 \%$ de plântulas emergidas. Nesses tratamentos a velocidade de emergência de plântulas também foi superior à dos outros.

Nos trabalhos de Bianchetti, Teixeira e Martins (1997), o método térmico também favoreceu a germinação de sementes de paricá, mas com valores inferiores (67\%) aos obtidos no presente trabalho (85\%), embora aqueles autores mantiveram as sementes por 24 horas em água após imersão a $100{ }^{\circ} \mathrm{C}$ por um minuto, ao passo que no atual a fonte de calor foi desligada imediatamente após as sementes terem sido imergidas, e foram retiradas assim que a temperatura da água igualou-se à do ambiente, em tempo aproximado de uma hora.

A germinação e o índice de velocidade de germinação foi superior nas sementes de paricá imersas em água a $100{ }^{\circ} \mathrm{C}$ e posterior permanência por quatro horas até o esfriamento, assim como no tratamento de desponte das sementes no lado oposto ao da emissão da radícula, com germinação de 88 e 98\%, superando a imersão em ácido sulfúrico (GARCIA; SOUZA; COLARES, 2005), resultado também verificado por
Martins et al. (2011), em que sementes de paricá tiveram germinação significativamente maior nesse método, em comparação a imersão em água a temperatura ambiente por 24 e 48 horas e em ácido muriático por 5; 10 e 20 minutos. Para sementes de guapuruvú (Schizolobium parahyba), a temperatura de $99{ }^{\circ} \mathrm{C}$ por um minuto elevou de forma significativa a germinação (98\%) em relação à testemunha $(0 \%)$ no período de 30 dias (MATHEUS; LOPES, 2007).

$\mathrm{Na}$ termoterapia, com o uso de água a $60^{\circ} \mathrm{C}$ a EP máxima foi de $5 \%$ e semelhante às sementes intactas, e a $80{ }^{\circ} \mathrm{C}$, embora superior às sementes intactas, não foi suficiente para proporcionaríndice recomendável deEP, ambos aos 30 DAS. Também com $80{ }^{\circ} \mathrm{C}$ e nas mesmas condições, Cruz e Carvalho (2006) verificaram no máximo $2 \%$ de germinação aos 24 dias. Resultado contrastante foi verificado por Silva Neto et al. (2007) em que a temperatura de $60{ }^{\circ} \mathrm{C}$ proporcionou germinação de $71 \%$ em sementes de paricá, semelhante estatisticamente à escarificação com lixa d'água por três minutos, assim como por Leão e Carvalho (1995), quando a imersão em água a $80^{\circ} \mathrm{C}$ por dois e quatro minutos, 
seguida de esfriamento natural por 24 horas, constituíram métodos eficientes para a quebra de dormência das sementes, proporcionando germinação superior a $85 \%$.

O possível enfraquecimento do tegumento quando as sementes de paricá são imersas em água a $100{ }^{\circ} \mathrm{C}$ deve-se a uma alteração no número de pontes de hidrogênio formadas entre polissacarídeos de parede, em especial entre microfibrilas de celulose, o que ocasiona uma menor agregação desses polissacarídeos, resultando em maior permeabilidade do tegumento ao influxo de água, em comparação às sementes intactas (SHIMIZU et al., 2011). Entretanto, como a embebição das sementes submetidas a esse método teve início 24 h após o tempo inicial de imersão, a curva de embebição indicou que a absorção de água foi lenta e que, ao final do período experimental, não houve estabilização do processo. Em sementes de Schizolobium parahyba (guapuruvu) a água fervente retira as ceras presentes no tegumento, o que diminui a impermeabilidade e permite a entrada de água e as trocas gasosas (ZAIDAN; BARBEDO, 2004), o que pode ocorrer também com sementes de paricá.

Em trabalho de campo sobre regeneração natural e banco de sementes de Schizolobium amazonicum em ambientes recém-desmatados, Rondon Neto, Sicuto e Ferreira (2008) verificaram que a regeneração natural foi maior na área cujo preparo foi realizado por meio de queima total, resultado que os autores atribuíram à superação da dormência tegumentar das sementes contidas no banco de sementes pela ação das altas temperaturas.

A resposta das sementes a temperaturas maiores pode ser uma característica adaptativa associada à sua ecologia, pois se trata de uma espécie secundária adaptada a áreas abertas como as clareiras na floresta que, por ocasião da eliminação das árvores de grande porte, ocorre aumento da passagem de luz e consequente aquecimento do solo, o que favorece o início da germinação e o desenvolvimento da plântula. Dessa forma, a dormência seria uma adaptação a ambientes perturbados, podendo as sementes permanecer no banco de sementes do solo e germinar apenas quando surgirem condições ideais ao estabelecimento das plântulas (OHASHI, 2005).

O uso de altas temperaturas para escarificar as sementes, embora tenha apresentado resultados promissores, requer atenção especial, conforme demonstraram Bianchetti, Teixeira e Martins (1997), quando a porcentagem de germinação de sementes de paricá foi reduzida em 36 pontos percentuais com o aumento do tempo de imersão de um para dois minutos e tornou as sementes inviáveis após 10 minutos. Os efeitos prejudiciais de altas temperaturas por determinados períodos foram evidenciados nos trabalhos de Matheus e Lopes (2007) em que a germinação de guapuruvu foi reduzida de 98 para $48 \%$ quando o período de imersão em água em ebulição subiu de um para cinco minutos. Esses cuidados já haviam sido enfatizados por Guerra et al. (1982) também para sementes de guapuruvu. Nos trabalhos de Bianchetti e Ramos (1981) com sementes dessa mesma espécie, a germinação foi estatisticamente semelhante entre quatro a dez minutos possivelmente porque, após esses períodos, foram mantidas na mesma água por 48 horas, procedimento que teria amenizado as consequencias de períodos prolongados sob altas temperaturas. Nesse sentido, Shimizu et al. (2011) ressaltam a necessidade de combinar uma determinada temperatura ao tempo de imersão das sementes, de forma que a embebição seja favorecida sem promover a morte dos tecidos.

Os resultados obtidos nesse trabalho permitem reduzir o tempo para tratamento térmico das sementes, uma vez que a semeadura ocorreu logo após o esfriamento da água (aproximadamente uma hora) e secagem superficial das sementes ao ar livre, enquanto na maioria dos trabalhos as sementes permanecem por 24 horas ou mais imersas em água à temperatura ambiente após a escarificação pré-semeadura.

Em relação aos métodos mecânicos de escarificação, Neves, Dalchiavon e Cargnin-Stieler (2010) conseguiram 99\% de germinação de sementes de paricá com a escarificação lateral do tegumento usando lixa manual, resultado que superou os tratamentos de imersão em hipoclorito de sódio $(2,5 \%)$ e em etanol $(92,8 \%)$, ambos por 25 minutos. Com procedimento idêntico e realizando semeadura logo após a escarificação, Cruz e Carvalho (2006) observaram estabilização do processo germinativo logo aos 12 DAS, método que proporcionou $92 \%$ de germinação, valores significativamente superiores aos de água a 60 e a $80{ }^{\circ} \mathrm{C}$. Azeredo et al. (2003) verificaram que a escarificação com lixa, que levou à germinação $95 \%$ das sementes de guapuruvu, superou o tratamento térmico com água a 50 e a $60{ }^{\circ} \mathrm{C}$, resultado igualmente verificado na velocidade de germinação. A escarificação manual com lixa levou sementes também de guapuruvu à germinação superior, em comparação com escarificação mecânica em escarificador florestal, imersão em ácido sulfúrico concentrado/5 min e imersão em água a $100^{\circ} \mathrm{C} / 10 \mathrm{~min} / 24 \mathrm{~h}$ de embebição em água a temperatura ambiente (SANTOS; SILVEIRA; CARGNELUTTI FILHO, 2003).

Para Shimizu et al. (2011) a escarificação com lixa pode ter causado pequenas fragmentações no tegumento da semente, tornando-o mais permeável ao influxo de água durante a hidratação e, por essa razão, a curva de embebição indicou rápida absorção de água 
pelos tecidos, com início em 12 horas após o início do condicionamento estabilizando-se após $72 \mathrm{~h}$ de imersão, resultados superiores aos proporcionados pela água fervente, assim como a germinação e a velocidade com que esta ocorre.

O uso do punção para produzir perfurações no tegumento também foi eficaz na eliminação da impermeabilidade tegumentar, com resultados satisfatórios já no $15^{\circ}$ dia. $O$ uso de instrumento perfurante foi recomendado por Lima Junior (2010).

A EP na escarificação com esmeril igualouse à da imersão em água a $100{ }^{\circ} \mathrm{C}$, alcançou $68 \%$, superou todos os outros tratamentos e estatisticamente se estabilizou nos primeiros 10 DAS, chegando a 95\% na contagem final. Durante a escarificação, a manutenção do tegumento pressionado contra o rebolo do esmeril por dois minutos provocou um aquecimento considerável na semente devido ao atrito, o que pode ter retirado ou diminuído a quantidade de ceras impermeabilizantes presentes no tegumento, citadas por Zaidan e Barbedo (2004). Esse método foi também utilizado e recomendado por Cruz e Carvalho (2006).

Plântulas anormais foram observadas em ácido sulfúrico por 35,40 e 50 minutos, água a $60{ }^{\circ} \mathrm{C}$, lixa, punção e esmeril. Nos outros tratamentos não houve formação de plântulas anormais mas as normais foram em quantidade ínfima, devido a forte dormência não superada. Dentre todos os tratamentos, a maior média de plantas anormais foi observada no tratamento com lixa (Figura 1).

Figura 1 - Plântulas anormais formadas a partir de sementes de Schizolobium amazonicum submetidas a tratamentos para superação de dormência

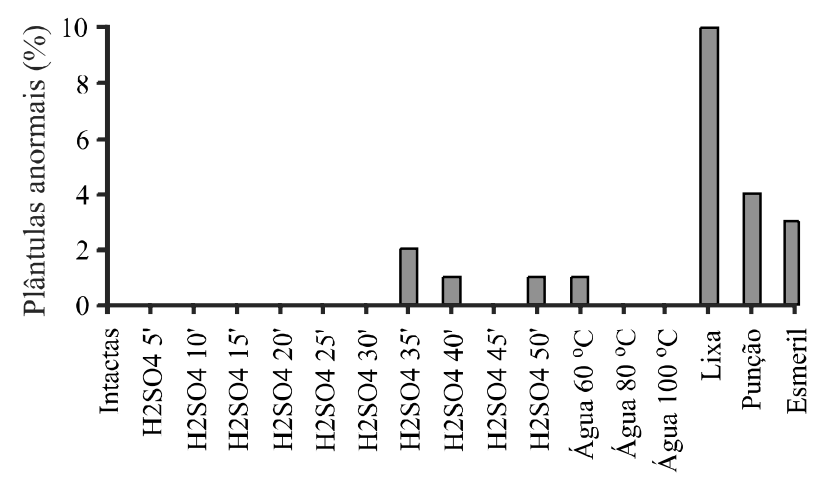

Tratamentos

Considerando que a escarificação com lixa foi feita na parte basal da semente, a tendência da plântula no inicio da germinação foi emergir por esta parte menos resistente e, como o tegumento não foi totalmente rompido, criou resistência física para o crescimento da planta.

O polígono de frequência relativa de emergência de plântulas (Figura 2) é polimodal para as sementes intactas e as imersas em ácido sulfúrico concentrado por 45 minutos, e praticamente unimodal para as tratadas com água fervente, lixa, esmeril e punção. É possível verificar que a EP de sementes intactas se distribuiu ao longo do tempo, com frequência máxima de $25 \%$, distribuição importante do ponto de vista ecológico, mas problemática em sistemas de produção de mudas.

Com a aplicação dos tratamentos os polígonos deslocaram-se para a esquerda, indicando redução no tempo, ou seja, nas sementes intactas a emergência teve início aos 15 DAS, ocorreu em um tempo médio (TME) de 24 dias, para um total (Nt) de quatro plântulas emergidas. Por outro lado, nos tratamentos com água fervente e esmeril, a emergência iniciou aos oito dias, com TME/Nt de 11,2/93 e 10,6/95, respectivamente. Com lixa e punção, as primeiras plântulas emergiram aos nove dias, com TME/Nt de $11,1 / 85$ e 10,4/89, respectivamente. Verificou-se também uma concentração da germinação nos períodos iniciais da avaliação (11 dias). A escarificação com esmeril adicionalmente proporcionou a concentração da emergência, que alcançou $67 \%$ e se completou em intervalo de tempo aproximado de 5,5 dias.

Os resultados confirmaram que sementes de paricá apresentam dormência que, embora seja considerada uma característica positiva do ponto de vista da botânica, é indesejável em um sistema de produção e análise de sementes, pois pode dificultar a realização dos teste de germinação e de vigor em laboratório e/ou campo, atrasar a fase de viveiro e causar heterogeneidade no tamanho das mudas. A escarificação com lixa pode eliminar ou minimizar esse problema, mas produz quantidade considerável de plântuas anormais, comparada aos métodos de imersão em água fervente, perfuração com punção e, principalmente, escarificação com esmeril elétrico.

Assim, a permeabilidade do tegumento proporcionada pelos diferentes tipos de escarificação, além de favorecer a hidratação da semente e auxiliar na eliminação ou redução dos teores de compostos fenólicos, sincroniza e intensifica a germinação e a velocidade com que ela ocorre, facilita a análise da viabilidade e do vigor em laboratório e em campo e permite a formação de mudas mais uniformes e em menor tempo. 
Figura 2 - Polígonos de frequência relativa de emergência de plantulas de Schizolobium amazonicum formadas a partir de sementes intactas e escarificadas em $\mathrm{H}_{2} \mathrm{SO}_{4} / 45$ min, água a $100{ }^{\circ} \mathrm{C}$, lixa, punção e esmeril elétrico
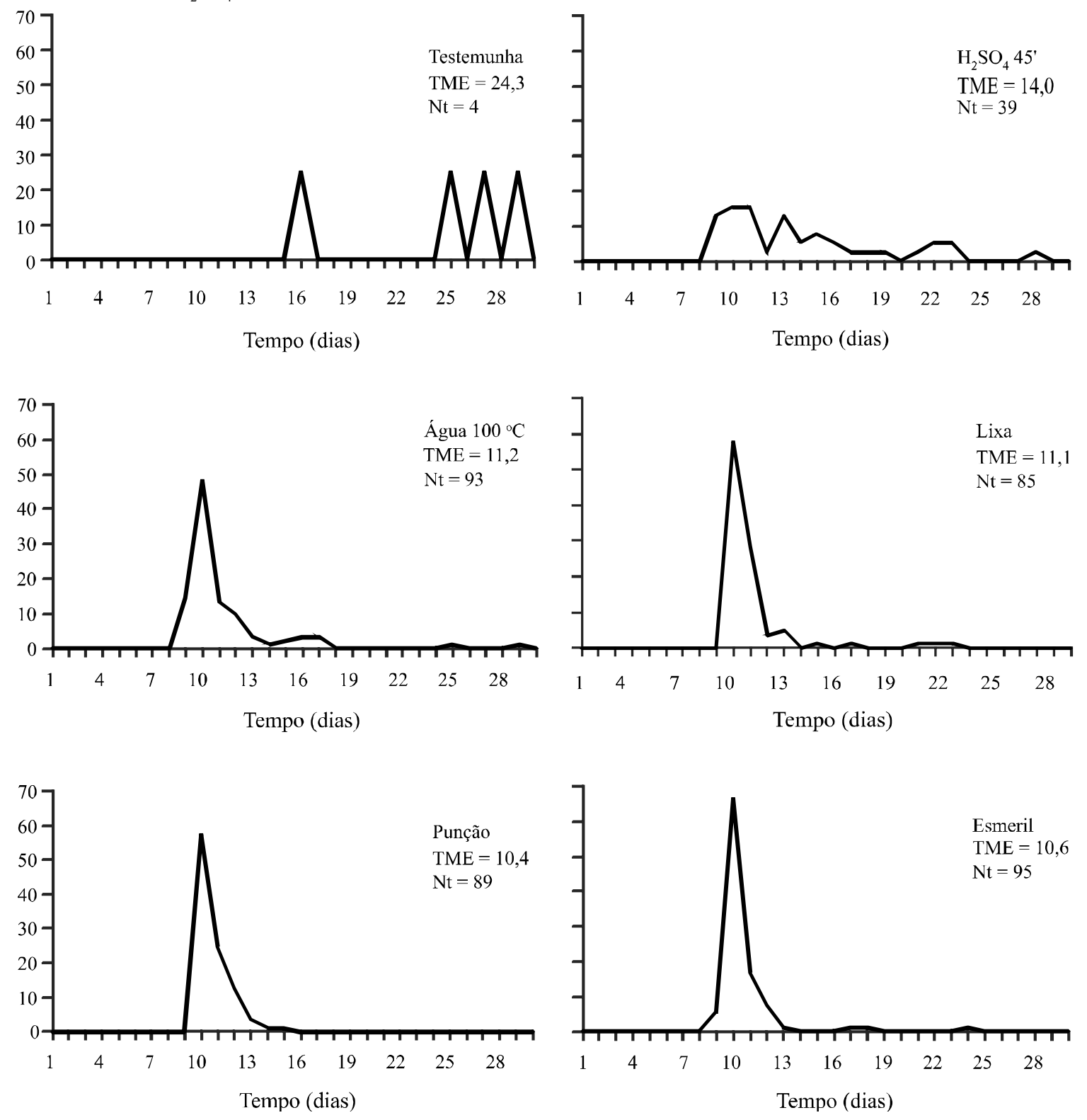

\section{CONCLUSÃO}

A perfuração do tegumento com punção, a imersão em água a $100^{\circ} \mathrm{C}$ e a escarificação com esmeril elétrico elimina a dormência tegumentar, acelera e uniformiza a germinação de sementes e a emergência de plântulas de Schizolobium amazonicum.

\section{REFERÊNCIAS}

AZEREDO, G. A. et al. Germinação em sementes de espécies florestais da mata atlântica (Leguminoseae) sob condições de casa de vegetação. Pesquisa Agropecuária Tropical, v. 33, n. 1, p. 11-16, 2003.

BIANCHETTI, A.; RAMOS, A. Quebra de dormência de sementes de guapuruvu (Schizolobium parahyba (Vellozo) Blake). Boletim de Pesquisa Florestal, n. 3, p. 69-76, 1981.

BIANCHETTI, A.; TEIXEIRA, C. A. D.; MARTINS, E. Tratamentos para superar a dormência em sementes debandarra (Schizolobium amazonicum Huber ex Ducke). Colombo: Embrapa Florestas, 1997. 2 p. (Comunicado Técnico, 20).

BRASIL. Ministerio da agricultura e Reforma Agraria. Secretaria Nacional de Defesa Agropecuaria. Regras para análise de sementes. Brasilia, 2009. 365 p. 
CARVAlHO, P. E. R. Paricá: (Schizolobium amazonicum). Colombo: Embrapa Florestas, 2007. 8 p. (Circular Técnica, 142)

CARVALHO, N. M.; NAKAGAWA, J. Sementes: ciencia, tecnologia e producao. Jaboticabal: FUNEP, 2000. 588 p.

CRUZ, E. D.; CARVALHO, J. E. U. Métodos de superação de dormência em Schizolobium amazonicum Huber ex Ducke (leguminosae - caesalpinioideae) seeds. Revista Brasileira de Sementes, v. 28, n. 3, p. 108-115, 2006.

CRUZ, E. D.; MARTINS, F. O.; CARVALHO, J. E. U. Biometria de Frutos e Sementes e Germinação de Jatobá-curuba (Hymenaea intermedia Ducke, Leguminosae - Caesalpinioideae). Revista Brasileira de Botânica, v. 24, n. 1, p. 161-165, 2001.

CRUZ,E.D.; CARVALHO, J.E.U.; QUEIROZ, R. J.B. Scarification with sulphuric acid of Schizolobium amazonicum Huber ex Ducke seeds - Fabaceae. Scientia Agricola, v. 64, n. 3, p. 308-313, 2007.

DAMIÃO FILHO, C. F.; MORO, F. V. Morfologia vegetal. $2^{a}$. ed. FUNEP: Jaboticabal, 2005. 172 p.

GARCIA, L. C.; SOUZA, S. G. A.; COLARES, L. M. L. Superação de dormência tegumentar em sementes de paricá (Schizolobium amazonicum). Informativo ABRATES, v. 15, n. $1 / 2 / 3$, p. $274,2005$.

GUERRA, M.P. et al. Comportamento de mudas de Schizolobium parahyba (Veloso) Blake, em viveiro, submetidas a diferentes métodos de quebra de dormência e sistemas de semeadura. Insula, n. 12, p. 39-52, 1982.

LABOURIAU, L. G. A germinação das sementes. Washington: OEA, 1983. $174 \mathrm{p}$.

LABOURIAU,L. G.; VALADARES, M.E. B. On the germination of seeds Calotropis procera (Ait.) Ait.f. Anais da Academia Brasileira de Ciências, v. 48, n. 2, p. 263-284, 1976.

LEÃO, N. V. M.; CARVALHO, J. E. U. Métodos para superação da dormência de sementes de paricá Schizolobium amazonicum Huber. ex Ducke. Informativo ABRATES, v. 5, n. 2, p. 169, 1995.

LIMA JUNIOR, M. J. V. (Ed.) Manual de Procedimentos para Análise de Sementes Florestais. UFAM: Manaus, 2010. 146 p.

MAGUIRE, J. D. Speed of germination: aid in selection and evaluation for seedling emergence and vigor. Crop Science, v. 2, n. 2, p. 176-177, 1962.

MARCOS FILHO, J. Fisiologia de sementes de plantas cultivadas. Piracicaba: Fealq, 2005. 495 p.

MARTINS, M. R. S. G. et al. Avaliação do ácido muriático e da imersão em água para superação de dormência de sementes de Schizolobium amazonicum Huber Ex Ducke. Informativo ABRATES, v. 21, n. 2, p. 149, 2011.

MARUYAMA, E.; UGAMOTO, M. Treatments for promoting germination of Parkia oppositifolia Benth and Schizolobium amazonicum Huber seeds. Journal of the Japanese Forest Society, v. 71, n. 5, p. 209-211, 1989.

MATHEUS, M. T.; LOPES, J. C. Termoterapia em Sementes de Guapuruvú (Schyzolobium parahyba (Vell.) Blake). Revista Brasileira de Biociências, v. 5, p. 330-332, 2007.
NAKAGAWA, J. Testes de vigor baseados na avaliacao de plantulas. In: KRZYZANOWSKI, F. C.; VIEIRA, R. D.; FRANCA NETO, J. B. (Ed.). Vigor de sementes: conceitos e testes. Londrina: ABRATES, 1999. Cap. 2, p. 2.1-2.24.

NEVES, G.; DALCHIAVON, F. C.; CARGNIN-STIELER, M. Superação da dormência em sementes de Schizolobium amazonicum. Uniciências, v. 14, n. 2, p. 271-285, 2010.

OHASHI, S. T. Varianilidade genética e fenotípica entre procedências de paricá Schizolobium parahyba var. amazonicum (Huber ex Ducke) Barneby visando seleção de materiais genéticos para sistemas agroflorestais. 2005, 107 f. Tese (Doutorado em Ciências Agrárias) - Universidade Federal Rural da Amazônia, Manaus.

PAOLI, A. A. S. Semente. In: SOUZA, L. A. (Org.) Anatomia do fruto e da semente. Ponta Grossa: Editora UEPG, 2006. p. 125-163.

PEREZ, S. C. J. G. A. Envoltórios. In: FERREIRA, A. G.; BORGHETTI, F. (Org.). Germinação: do básico ao aplicado. Porto Alegre: Artmed, 2004. p. 125-134.

RONDON NETO, R. M.; SICUTO, A. S.; FERREIRA, M. A. C. Regeneração natural de pinho-cuiabano (Schizolobium amazonicum huber ex ducke) após sistemas de desmatamentos diferenciados. In: SIMPÓSIO DE PÓS-GRADUAÇÃO EM CIÊNCIAS FLORESTAIS, 5, 2008, Brasília. Resumos... Brasília: Universidade de Brasília, Programa de Pós-Graduação em Ciências Florestais, 2008. p. 955-958.

SANTOS, F.; SILVEIRA, M. A. M.; CARGNELUTTI FILHO, A. Superação de dormência em sementes de guapuruvu. Informativo ABRATES, v. 13, n. 3, p. 179, 2003.

SCHMIDT, L. Dormancy and pretreatment. In: OLSEN, K. (Ed.). Guide to handling of tropical and subtropical forest seeds. Humlebaek: Danida Forest Seed Center, 2000. cap. 9, p. $263-303$.

SHIMIZU, E. S. C. et al. Aspectos fisiológicos da germinação e da qualidade de plântulas de Schizolobium amazonicum em resposta à escarificação das sementes em lixa e água quente. Revista Árvore, v. 35, n. 4, p. 791-800, 2011.

SILVA, F. A. S. E.; AZEVEDO, C. A. V. Principal Components Analysis in the Software Assistat-Statistical Attendance. In: WORLD CONGRESS ON COMPUTERS IN AGRICULTURE, 7., Reno, 2009. Anais... Reno - American Society of Agricultural and Biological Engineers, 2009.

SILVA NETO, P. A. et al. Métodos para superação de dormência em sementes de paricá (Schizolobium amazonicum Huber ex. Ducke) (Leguminosae - Caesalpinioideae). Revista Brasileira de Biociências, v. 5, p. 732-734, 2007.

SOUSA, D. B.; CARVALHO, G. S.; RAMOS, E. J. A. Paricá Schizolobium amazonicum Huber ex Ducke. Informativo Técnico, Rede Sementes do Amazônia, n. 13, 2005.

ZAIDAN, L. B. P.; BARBEDO, C. J. Quebra de dormência em sementes. In: FERREIRA, A. G.; BORGHETTI, F. (Org.). Germinação: do básico ao aplicado. Porto Alegre: Artmed, 2004. p. 135-146. 